\title{
To study the painless labour by epidural analgesia and its effects on cardiotocographic parameters and labour
}

\author{
Neena Gupta ${ }^{*}$, Sachidanand Gupta ${ }^{2}$, Apurva Agarwal', Shaily Agarwal, \\ Seema Dwivedi ${ }^{1}$, Anchal Singh ${ }^{1}$
} ${ }^{1}$ Department of Obstetrics \& Gynaecology, ${ }^{2}$ Department of Anaesthesiology, G.S.V.M. Medical College, Kanpur-
208002, Uttar Pradesh, India

Received: 31 October 2013

Accepted: 13 November 2013

*Correspondence:

Dr. Neena Gupta,

E-mail: neena.gupta2211@gmail.com

(C) 2013 Gupta $\mathrm{N}$ et al. This is an open-access article distributed under the terms of the Creative Commons Attribution Non-Commercial License, which permits unrestricted non-commercial use, distribution, and reproduction in any medium, provided the original work is properly cited.

\begin{abstract}
Background: Epidural analgesia is a central nerve block technique achieved by injection of a local anesthetic close to the nerves that transmit pain and is widely used as a form of pain relief in labor. The objective was to study the effect of epidural analgesia on cardiotocographic parameters and relief of pain, effect on course of labor and its outcome in terms of duration, any complications and mode of delivery.

Methods: A prospective observational study was done on 100 subjects. They were randomly divided into study and control groups, study group (50) were given epidural analgesia after $3 \mathrm{~cm}$ dilatation while control group (50) did not receive any analgesic. NST was taken before and after analgesia, course of labor, duration of labor, mode of delivery.

Results: The study shows no significant effect of epidural analgesia on the duration of labor, mode of delivery, and CTG parameters.

Conclusion: Epidural analgesia group shows better pain relief. It favors normal course of labor, no effect on cardiotocographic parameters. Subjects in study group were more satisfied.
\end{abstract}

Keywords: Epidural analgesia, Cardiotocographic parameters (CTG), Nonstress test, Labour

\section{INTRODUCTION}

Pregnancy and childbirth is the most precious gift for women given by God. The only thing which makes a pregnant lady curious, anxious and fearful is the pain during delivery.

Labor pain has been described by most as the most painful experience a woman can have in her lifetime. Efforts have been taken for centuries to alleviate this labor pain. The methods of pain relief are non pharmacological and pharmacological. The pharmacological methods of pain relief are inhalational analgesics, narcotics and epidural analgesia.

Epidural analgesia is a central nerve blockade technique, which involves the injection of a local anesthetic into the lower region of the spine close to the nerves that transmit painful stimuli from the contracting uterus and birth canal. The anesthetic inhibits nerve conduction by blocking sodium channels in nerve membranes, thereby preventing the propagation of nerve impulses along this fibres. Blocking of painful impulses from the nerves as they cross the epidural space results in analgesia which should be apparent within 10 to 20 minutes of administration.

Epidural analgesia is considered to be effective for reducing pain in labor (Brownridge ${ }^{1}$ 1991; Howell ${ }^{2} 2001$ ).

\section{METHODS}

This was a prospective study conducted in upper India sugar exchange maternity hospital department of Obstetrics and Gynecology, GSVM Medical College, Kanpur. 


\section{Inclusion criteria}

Healthy patients with Cephalic presentation, Singleton pregnancy, 37-42 weeks gestation.

\section{Exclusion criteria}

Women with pre-eclampsia, Diabetes, Preterm labor, Bleeding disorders, Scoliosis, Allergy to study drug, Blood in CSF in epidural catheter.

Subjects of present study were divided into 2 groups, the control group included patients with healthy pregnancy who were not given epidural analgesia and study group included patients who had epidural analgesia. Written informed consent was obtained from healthy parturients with cephalic singleton pregnancy from 36-42 weeks gestation who requested labor analgesia. An intravenous line was secured and a preload of $500 \mathrm{ml}$ of ringer lactate solution was given. When cervix was $3-4 \mathrm{~cm}$ dilated i.e., patient was in active labour epidural catheter of 18 gauze was inserted. The drug injected was $0.125 \%$ bupivacaine. The repeat top up doses were given on patient's demand. All these patients were followed up to delivery. Labor was managed and mode of delivery and time of delivery was noted.

\section{Statistical analysis}

The statistical significance of observed difference between control and study groups was determined by students ' $\mathrm{t}$ ' test 'chi square' test.

\section{RESULTS}

100 patients were in spontaneous labour were included in the study (50 in study group and 50 in control group).

In our study, distribution of cases according to age groups showed that majority of patients belonged to age group $18-23(60 \%)$ in study and $49 \%$ in control groups and is statistically insignificant. The maximum number of patients were lying between 37-40 weeks of gestation in both the groups and is statistically insignificant. The mean gestational age is 38.2 with a standard deviation of 1.3626. The majority of the patients belonged to middle socioeconomic status $(52 \%)$ while maximum patients in control group were lying in low socioeconomic status. This was statistically insignificant. The educated patients opted more for epidural analgesia. This was statistically insignificant (Table 1).

Table 1: Sociodemographic profile of study and control groups.

\begin{tabular}{|c|c|c|c|c|c|c|}
\hline \multirow{3}{*}{$\begin{array}{l}\text { Sociodemographic } \\
\text { Parameters }\end{array}$} & & \multicolumn{2}{|c|}{ Study Group } & \multicolumn{2}{|c|}{ Control Group } & \multirow[t]{2}{*}{ p value } \\
\hline & & \multicolumn{2}{|c|}{$(n=50)$} & \multicolumn{2}{|c|}{$(n=50)$} & \\
\hline & & $\mathrm{N}$ & $\%$ & $\mathrm{~N}$ & $\%$ & \\
\hline \multirow[t]{3}{*}{ Age } & $18-23$ & 30 & 60 & 24 & 49 & mean age 23.72 \\
\hline & $24-29$ & 18 & 46 & 22 & 40 & $\mathrm{p}>0.05$ \\
\hline & $30-35$ & 2 & 4 & 3 & 6 & \\
\hline$>35$ & 0 & 0 & 1 & 2 & & \\
\hline Gest age & $37-40$ & 47 & 94 & 45 & 90 & Mean $38.2 \pm 1.32$ \\
\hline$>40$ & & 3 & 6 & 5 & 10 & $\mathrm{p}>.05$ \\
\hline \multirow[t]{3}{*}{$\begin{array}{l}\text { Socioeconomic } \\
\text { Low Status }\end{array}$} & & 22 & 44 & 29 & 58 & chi $=1.96$ \\
\hline & Middle & 26 & 52 & 20 & 40 & $\mathrm{p}>.05$ \\
\hline & High & 2 & 4 & 1 & 2 & \\
\hline \multirow[t]{4}{*}{ Educational Status } & Primary & 5 & 10 & 10 & 20 & $\mathrm{chi}=5.09$ \\
\hline & High school & 8 & 16 & 15 & 30 & $\mathrm{p}>.05$ \\
\hline & Intermediate & 25 & 50 & 18 & 36 & \\
\hline & Graduate & 12 & 24 & 8 & 16 & \\
\hline \multirow[t]{3}{*}{ Gravida } & G1 & 42 & 84 & 42 & 84 & $\mathrm{p}>.05$ \\
\hline & $\mathrm{G} 2$ & 7 & 14 & 5 & 10 & \\
\hline & G3 & 1 & 2 & 3 & 6 & \\
\hline \multirow[t]{2}{*}{ Residence } & Urban & 37 & 74 & 15 & 30 & $\mathrm{p}>.05$ \\
\hline & Rural & 13 & 26 & 35 & 70 & \\
\hline
\end{tabular}


The administration of epidural analgesia did not significantly prolong the first and second stages of labour in both primigravida and multigravida (Table 2).

The study shows that greater number of patients delivered with oxytocin augmentation and need was greater in epidural group but there was no significant difference (Table 3).

The rate of vaginal deliveries, instrumental deliveries and caesarean deliveries were not statistically different between the two groups (chi=0.12, p>0.05) (Table 4).
The administration of epidural analgesia did not significantly affect the baseline fetal heart and variability (Table 5).

There was no effect of epidural analgesia on the number of accelerations and decelerations (Table 6).

Table 2: Duration of labour.

\begin{tabular}{|llllll|}
\hline Stages of labour & Primigravida & & Multigravida & & p value \\
\hline & Study group & Control group & Study group & Control group & \\
\hline & $\mathrm{n}=42$ & $\mathrm{n}=42$ & $\mathrm{n}=8$ & $\mathrm{n}=8$ & $\mathrm{p}>0.05$ \\
\hline $\begin{array}{l}\text { Duration of } 1^{\text {st }} \\
\text { stage }\end{array}$ & $5.500 \pm 1.2025$ & $5.842 \pm .9733$ & $3.8750 \pm .8345$ & $4.00 \pm 2.673$ & \\
\begin{tabular}{l} 
Hrs (mean $\pm \mathrm{SD})$ \\
\hline $\begin{array}{l}\text { Duration of } 2^{\text {nd }} \\
\text { stage } \\
\text { min }(\text { mean } \pm \mathrm{SD})\end{array}$
\end{tabular} & $28.5526 \pm 10.83$ & $29.47 \pm 9.9858$ & $17.500 \pm 3.7796$ & $16.25 \pm 5.1755$ & $\mathrm{p}>0.05$ \\
\hline
\end{tabular}

Table 3: Requirement of oxytocin augmentation in labour.

\begin{tabular}{|c|c|c|c|c|c|c|c|c|c|}
\hline \multirow[t]{3}{*}{ Duration } & \multicolumn{4}{|c|}{ Primigravida } & \multicolumn{4}{|c|}{ Multigravida } & chi $=0.68$ \\
\hline & \multicolumn{2}{|c|}{ Study group } & \multicolumn{2}{|c|}{ Control group } & \multicolumn{2}{|c|}{ Study group } & \multicolumn{2}{|c|}{ Control group } & \\
\hline & $\mathrm{n}=42$ & $\%$ & $\mathrm{n}=42$ & $\%$ & $\mathrm{n}=8$ & $\%$ & $\mathrm{n}=8$ & $\%$ & \\
\hline $\begin{array}{l}<8 \text { hrs } \\
\text { without } \\
\text { oxytocin }\end{array}$ & 9 & 21.42 & 11 & 26.19 & 3 & 37.5 & 2 & 40 & \\
\hline $\begin{array}{l}<8 \text { hrs with } \\
\text { oxytocin }\end{array}$ & 32 & 76.19 & 29 & 69.04 & 5 & 62.5 & 660 & 60 & $\mathrm{p}>0.05$ \\
\hline $\begin{array}{l}>8 \mathrm{hrs} \text { with } \\
\text { oxytocin }\end{array}$ & 1 & 2.3 & 2 & 4.76 & - & - & & & \\
\hline
\end{tabular}

Table 4: Mode of delivery.

\begin{tabular}{|lllll|}
\hline Mode of delivery & Epidural group $\mathbf{n = 5 0}$ & Control group $\mathbf{n = 5 0}$ & chi=0.12 & \\
\hline & no $\%$ & no $\%$ & p $>0.05$ & \\
\hline Normal vaginal & 46 & 92 & 45 & 90 \\
\hline Assisted & - & 2 & 4 & 6 \\
\hline Caesarean & 4 & 8 & 3 & 6 \\
\hline
\end{tabular}


Table 5: Effect on baseline fetal heart rate and variability.

\begin{tabular}{|lllllll|}
\hline Parameters & \multicolumn{5}{c}{ Before epidural $\mathbf{n = 5 0}$} & \multicolumn{2}{c|}{ After epidural $\mathbf{n = 5 0}$} & \\
\hline Baseline FHR & $<120$ & $\mathrm{n}$ & $\%$ & $\mathrm{n}$ & $\%$ & \\
\hline & $120-140$ & 22 & 44 & 24 & 48 & $\mathrm{p}>0.05$ \\
\hline $140-160$ & 28 & 56 & 22 & 44 & & \\
\hline$>160$ & - & - & $2^{*}$ & 4 & & \\
\hline Variability & $<5$ & - & - & 3 & 6 & chi $=0.64$ \\
\hline $5-15$ & 26 & 52 & 24 & 48 & $\mathrm{p}>0.05$ & \\
\hline $15-25$ & 24 & 48 & 22 & 46 & & \\
\hline$>25$ & - & - & 1 & 2 & & \\
\hline
\end{tabular}

Table 6: Effect of epidural analgesia on number of accelerations and decelerations.

\begin{tabular}{|lllllll|} 
& & \multicolumn{3}{c}{ Before epidural $\mathrm{n}=\mathbf{5 0}$} & \multicolumn{3}{c|}{ After epidural $\mathrm{n}=\mathbf{5 0}$} & \\
\hline & & $\mathrm{n}$ & $\%$ & $\mathrm{n}$ & $\%$ & \\
\hline No. of acc. & $<1$ & - & - & & 1 & 2 \\
\hline $1-2$ & - & - & & 1 & 2 & \\
\hline$>2$ & 50 & 100 & 48 & 86 & & \\
\hline No. of dece. early & 8 & 16 & 6 & 12 & chi $=4.11$ & \\
\hline & Late & - & - & 3 & 6 & $\mathrm{p}>0.05$ \\
\hline & Variable & - & - & $1 *$ & 2 & \\
\hline
\end{tabular}

\section{DISCUSSION}

The administration of epidural analgesia has no effect on the duration of first and second stage of labour in both primigravida and multigravida. Mousa WF, et $\mathrm{al}^{3}$ (2010) also found similar results. A study was conducted by Wesam Farid Mousa, et $\mathrm{al}^{4}$ (2012) on the effect of epidural analgesia on the duration of labor in primiparous parturients. They found that it has no clear effect on the duration of the first stage, whereas the second stage is more constantly prolonged. The differences in the results were due to the additional top up doses of analgesia being administered in their study in second stage of labour. Another study conducted by Howell $\mathrm{CJ}^{5}$ (2000) found that epidural analgesia was associated with longer first and second stages of labour. This difference is due to the analgesia being given at active stage of labour in our study.

In our study showing distribution of patients according to oxytocin augmentation greater number of patients delivering in less than 8hours required oxytocin augmentation during labour (32\%). This difference was statistically insignificant. A study was conducted by Mousa WF, et $\mathrm{al}^{3}$ (2012) the maximal oxytocin dose was significantly higher in the epidural group

In our study there was no difference in the rate of normal vaginal deliveries, instrumental deliveries and caesarean section .Study done by Wesam Farid Mousa, et $\mathrm{al}^{4}$ (2012) found similar results.

Chung KD, et $\mathrm{al}^{6}$ (1990) found that painless labor with epidural analgesia would decrease the rate of cesarean section, but increase the frequency of using forceps and vacuum for labor. The rate of normal spontaneous delivery is low as compared with those not receiving epidural analgesia for painless labor. However, painless labor bears no relation to the labour course nor discernible significance to the Apgar score of the newborn babies.

Thorp $\mathrm{JA}^{7}$ (1996) concluded that Epidural analgesia is a safe and effective method of relieving pain in labor, but is 
associated with longer labor, more operative intervention, and increases in cost.

In our study there was no effect on significant effect on cardiotocographic parameters in epidural and control groups.

In our study majority of the patients had their basal fetal heart between 120-140 and 140-160. ${ }^{2}$ Patients had fetal heart $<120$ due to cord around neck and prolonged second stage of labour. ${ }^{2}$ Patients had fetal heart $>160$ due to meconium stained liquor. There was no significant association. In our study there was statistical highly significant difference in the degree of pain relief in epidural group and control group $(\mathrm{p}<0.0001)$.

\section{CONCLUSION}

The study shows that the epidural analgesia for painless labour has no significant effect on the duration of labour, course of labour, mode of delivery. No increase in the number of assisted deliveries and caesarean section has been seen. The epidural analgesia shows no effect on the cardiotocographic parameters.

\section{Funding: None}

Conflict of interest: None

Ethical approval: Approved by the Institutional Ethics Committee

\section{REFERENCES}

1. Brownridge P. Treatment options for the relief of pain during childbirth. Drugs 1999; 41(1):69-80.

2. Howell CJ, Kidd C, Robert W, Upton P, Lucking L, Jones PW, Johanson RB: A randomized controlled trial of epidural compared with non epidural analgesia in labour. BJOG $2001 \mathrm{Jan} ; 108(1): 27-23$.

3. Mousa WF, Al-Metwalli RR, Mostafa MM. Epidural analgesia during labor- $0.5 \%$ lidocaine with fentanyl vs $0.08 \%$ ropivacaine with fentanyl. Middle East J Anesthesiol. 2010;20:521-7.

4. Wesam Farid Mousa, Roshdi Al-Metwalli, and Manal Mostafa1 Epidural analgesia during labor vs no analgesia: A comparative study Saudi J Anaesth. 2012 Jan-Mar; 6(1): 36-40.

5. Howell CJ. Epidural versus non-epidural analgesia for pain relief in labour. Cochrane Database Syst Rev. 2000;2:CD000331.

6. Chung KD, Liu WM, Wu YW, Hui YL. Painless labor and instrumentation. Ma Zui Xue Za Zhi. 1990 Sep;28(3):303-6.

7. Thorp JA, Breedlove G. Epidural analgesia in labor: an evaluation of risks and benefits. Birth. 1996 Jun;23(2):63-83.

DOI: $10.5455 / 2320-1770 . i j r \operatorname{cog} 20131234$

Cite this article as: Gupta N, Gupta S, Agarwal A, Agarwal S, Dwivedi S, Singh A. To study the painless labour by epidural analgesia and its effects on cardiotocographic parameters and labour. Int J Reprod Contracept Obstet Gynecol 2013;2:666-70. 